\title{
Communicating genetic information in families - a review of guidelines and position papers
}

\author{
Laura E Forrest ${ }^{1,2,3}$, Martin B Delatycki ${ }^{2,3,4}$, Loane Skene $^{5}$ and MaryAnne Aitken*,1,3
}

${ }^{1}$ Genetics Education and Health Research, Murdoch Childrens Research Institute, Royal Children's Hospital, Parkville, Australia; ${ }^{2}$ Bruce Lefroy Centre for Genetic Health Research, Murdoch Childrens Research Institute, Royal Children's Hospital, Parkville, Australia; ${ }^{3}$ Department of Paediatrics, The University of Melbourne, Melbourne, Australia; ${ }^{4}$ Genetic Health Services Victoria, Royal Children's Hospital, Parkville, Australia; ${ }^{5}$ The Melbourne Law School, The University of Melbourne, Melbourne, Australia

This article aims to review ethical and clinical guidelines and policies addressing the communication of genetic information in families. Websites of national and regional bioethics committees, national human genetics societies, international health organisations, genetic interest groups and legal recommendations committees were searched for guidelines and policies. The databases Medline, Web of Science and Google Scholar were also utilised to search for additional guidelines relating to the communication of genetic information in families. The guidelines and policies included in this review are limited to those available in English. The search resulted in guidelines from 18 international, regional and national organisations from six countries pertaining to family communication of genetic information. The following ideals were common in their guidelines: (1) individuals have a moral obligation to communicate genetic information to their family members; (2) genetic health professionals should encourage individuals to communicate this information to their family members; and (3) genetic health professionals should support individuals throughout the communication process. The difference between the organisations' guidelines was the inclusion of information about the role of the health professional in supporting clients during the process of communicating genetic information to their family members. Only two recommendations suggested that the health professional should support their clients by identifying at-risk family members, but more guidelines recommended that directive counselling should be undertaken to encourage clients to communicate genetic information to their family members. In conclusion, the guidelines provide an overview of the role that genetic health professionals may undertake; however, there are gaps that need to be addressed.

European Journal of Human Genetics (2007) 15, 612-618. doi:10.1038/sj.ejhg.5201822; published online 28 March 2007

Keywords: communication; families; genetic information; guidelines

${ }^{*}$ Correspondence: Dr M Aitken, Genetics Education and Health Research, Murdoch Childrens Research Institute, 10th Floor, Royal Children's Hospital, Flemington Road, Parkville VIC 3052, Australia.

Tel: + 61383416308 ; Fax: + 61383416212 ;

E-mail: maryanne.aitken@mcri.edu.au

Received 18 October 2006; revised 15 February 2007; accepted 21 February 2007; published online 28 March 2007
Introduction

Over the last two decades major developments in human genetic research have resulted in the molecular and phenotypic details of almost 2000 different genetic conditions being determined. ${ }^{1}$ Utilising these advances for genetic testing not only provides information about an individual undergoing testing but also has implications about health and reproductive decision making for their 
family members. ${ }^{2-4}$ Individuals who undergo genetic testing need support and education about the implications genetic information carries for themselves and for their relatives.

The counselling process before and after testing provides an opportunity for the genetic health professional to assist individuals to understand the importance of communicating genetic information to their at-risk relatives. Nevertheless, in many countries, the responsibility of disseminating genetic information to family members lies largely with the individual.

The possibility that the individual will not disclose genetic information to family members raises an ethical dilemma for health professionals. This issue is problematic as health professionals will have to weigh up their patient's right to confidentiality versus the potential for harm to uninformed family members. ${ }^{5,6}$ This issue is well documented by research ${ }^{7-11}$ and a comprehensive review of guidelines has been published recently. Godard et al ${ }^{12}$ categorises the guidelines into those requiring an individual's consent to inform family members, where 'exceptional circumstances' allow disclosure to family members, or where 'special considerations' can account for disclosure. ${ }^{12}$ The American Society of Human Genetics Social Issues Subcommittee on Familial Disclosure also provides an overview of guidelines titled Professional disclosure of familial genetic information, which includes international, regional and national positions on health professionals disclosing genetic information to uninformed at-risk family members.

Despite the availability of literature and guidelines examining non-disclosure of genetic information, research suggests that many individuals do attempt to communicate genetic information to their family members. ${ }^{13}$ Although these individuals are not actively blocking disclosure of genetic information to their family members, communication of this information is a complicated process and can be affected by family dynamics ${ }^{4,14-16}$ family history, ${ }^{17}$ personal understanding, ability to explain genetic concepts, and family member's interest and ability to understand the information. Sermijn et al ${ }^{18}$ demonstrated that when individuals communicated genetic information, it did not result in family members gaining a good understanding and awareness of the genetic condition.

Given the apparent difficulties individuals encounter when communicating genetic information to family members, it may be necessary for genetic health professionals to play a greater role after a genetic test result is given, to support and assist individuals to inform their families. More support from health professionals may result in a greater number of family members becoming aware and gaining a better understanding of their genetic risk. Ethical debate apropos the merits of direct contact from clinical services to at-risk family members encompasses opinions ranging from at-risk relatives' right not to know ${ }^{19}$ to professionals' moral duty to inform..$^{20}$

This review presents the existing guidelines, recommendations, reports and policy papers related to the communication of genetic information in families. It also examines the similarities and differences, illustrates general themes and stances, and identifies gaps within recommendations and guidelines.

\section{Methods}

\section{Data sources}

The data sources were publications in English collected from the websites of national human genetics societies, bioethics committees, research institutes, legal recommendations committees, and regional and international health organisations. Additional organisations were sourced via links from the website of the European Society of Human Genetics (ESHG) including a search of each of the ESHG members' websites and the International Federation of Human Genetics Societies' website. To ensure all relevant guidelines were included, the databases of Medline, Web of Science and Google Scholar were searched using the keywords communic*, family communic*, guideline*, recommendation* and report*.

\section{Study selection}

Publications were eligible for inclusion in this review if they were reports, guidelines publications, position papers, recommendations or statements that included commentary about the ethics of genetic testing, genetic information, genetic screening or guidelines for genetic health professionals' practice. The search excluded publications focussing on genetic registers or other unrelated genetic research guidelines.

\section{Results}

In total, 19 guidelines met the inclusion criteria, emanating from 18 different organisations from six countries, three regional and three international organisations. The guidelines were published by national human genetics societies (six), ${ }^{21-26}$ bioethics committees and councils (four), ${ }^{27-30}$ genetics commissions (two), ${ }^{31,32}$ international health organisations (two), ${ }^{33,34}$ regional health organisations (two), ${ }^{35,36}$ a research institute (one) ${ }^{37}$ and a consumer group (one). ${ }^{38}$

\section{Key themes}

Genetic information has familial implications Many of the published guidelines begin by explicitly stating that genetic information is not only relevant to the individual receiving it, but also to their family members ${ }^{21,22,27-29,31,33-36,38,39}$ due to 'genetic heritage', 34 and therefore may have consequences for family planning and personal health of 
relatives $^{21,31,36}$ who are unaware of their risk. ${ }^{38}$. Five organisations are more explicit about how genetic information has implications for, specifying 'blood relatives', ${ }^{22}$ 'the whole family, ascendants, descendants, collaterals, and possibly spouses', 27 'future children', 36 'relatives, including offspring', 35 or 'family' [which] needs to be understood as covering an extended set of relatives linked by blood ties or by marriage or by both' ${ }^{30}$ Other guidelines simply specify 'family', 21,28,29 'family members' ${ }^{31}$ or 'relatives $^{21}$ to cover the broad spectrum of those who are at risk of a genetic condition. 'The 'true patient' may be a family' $^{34}$ is an apt summation to justify the dissemination of genetic information to family members and is used as a platform for such discussion by many of the organisations. For a summary of guidelines, see Table 1 .

Should genetic health professionals adopt a directive stance? There is a general consensus regarding the responsibilities of genetic health professionals to, at minimum, inform clients about the implications that genetic information holds for their family members. ${ }^{23}$ However, many guidelines take a more in-depth stance recommending that genetic health professionals actively encourage patients to disclose genetic information to family members. ${ }^{24,27,28,30-32,34,37,38}$ The language used in the publications varies from a passive stance, 'it is suggested to the subject the result be disclosed to family members', ${ }^{24}$ to more strongly worded 'a doctor must do everything in his power to convince a patient ${ }^{27}$ and 'medical geneticists are entitled to ask assertively, if not to require'. ${ }^{34}$ However, within this spectrum, lie more moderate views, such as, 'individuals can be encouraged to share information by considerate and patient discussion of the issues' ${ }^{38}$ In contrast, one committee's guidelines do not concur with the consensus, stating, 'geneticists who press for the information to be relayed ... violate patient autonomy'. ${ }^{21}$ There is no generalised approach taken by the national human genetics societies' guidelines reviewed towards encouragement to disclose; instead these recommendations originate from a spectrum of the organisations included. For a summary of guidelines, see Table 2 .

\begin{abstract}
Should genetic health professionals identify at-risk family members? Only two organisations explicitly stated that 'genetic services' or 'clinics' should assist their clients by identifying the family members who are at risk of also inheriting the genetic condition. ${ }^{26,31}$ The ESHG states that 'genetic services should support the identification of ... relatives who are at risk' but goes on to qualify that statement with 'who are at risk of serious genetic disorders'. ${ }^{26}$ The UK Human Genetics Commission takes a more generalistic view by suggesting that 'clinics may support and indeed encourage the process of family communication and genetic counsellors may give advice on how such information may be disseminated to those for whom it may be most relevant'. ${ }^{31}$ Also providing some guidance is the UK Nuffield Council on Bioethics, discussing that individuals require information about the implications of a positive test result for their 'future and existing children, and for other family members' ${ }^{30}$ before deciding whether to undertake a genetic test. For a summary of guidelines, see Table 3 .
\end{abstract}

Do individuals have a moral obligation to inform family members? Some guidelines also discuss the role of the individual and the family when examining the situation involving communication of genetic information. The Nuffield Council states that both individuals and family members have responsibilities to be willing to give and receive genetic information. ${ }^{30}$ Other publications discuss the ethical principal of non-maleficence ${ }^{34}$ and encourage individuals to 'act ethically' ${ }^{38}$ by sharing the genetic

Table 1 Summary of guidelines

\begin{tabular}{|c|c|c|}
\hline Location & Organization & Recommendation \\
\hline International & World Health Organization (2003) & In genetics, the 'true patient' may be a family with a shared genetic heritage \\
\hline Regional & European Commission (2004) & $\begin{array}{l}\text { The fact that genetic testing has consequences not only for the } \\
\text { individual, but also for relatives, including offspring }\end{array}$ \\
\hline Australia & $\begin{array}{l}\text { Human Genetics Society of Australasia } \\
\text { (1999) }\end{array}$ & ... information about the gene mutation belongs to all blood relatives \\
\hline France & $\begin{array}{l}\text { National Consultative Ethics } \\
\text { Committee for Health and Life } \\
\text { Sciences (2003) }\end{array}$ & $\begin{array}{l}\ldots \text { the results of a genetic test are not the sole concern of the proband. } \\
\text { They also affect the whole family, ascendants, descendants, collaterals } \\
\text { and possibly spouses }\end{array}$ \\
\hline Germany & $\begin{array}{l}\text { German Society of Human Genetics } \\
(2000)\end{array}$ & $\begin{array}{l}\text { Information that becomes available from medical genetic studies ... is } \\
\text { also relevant to the personal health, family planning and future plans of } \\
\text { family members and relatives }\end{array}$ \\
\hline $\begin{array}{l}\text { United } \\
\text { Kingdom }\end{array}$ & Nuffield Council on Bioethics (1993) & $\begin{array}{l}\text { 'Family' needs to be understood as covering an extended set of relatives } \\
\text { linked by blood ties or by marriage or by both.... These points will be } \\
\text { particularly important in considering issues of consent, confidentiality } \\
\text { and data protection }\end{array}$ \\
\hline
\end{tabular}


Table 2 Summary of guidelines

\begin{tabular}{|c|c|c|}
\hline $\begin{array}{l}\text { Should genetic } \\
\text { Location }\end{array}$ & $\begin{array}{l}\text { Orofessionals adopt a directive stance? } \\
\text { Organization }\end{array}$ & Recommendation \\
\hline International & World Health Organization (2003) & $\begin{array}{l}\text { Medical geneticists are entitled to ask assertively, if not to require, } \\
\text { that the identified individual or parents help in contacting relatives } \\
\text { so that they may be informed about specific risks } \\
\text { 'Non-directive counselling' is not appropriate in these situations }\end{array}$ \\
\hline France & $\begin{array}{l}\text { National Consultative Ethics } \\
\text { Committee for Health and Life } \\
\text { Sciences (2003) }\end{array}$ & $\begin{array}{l}\text {... the attitude of a physician who did not do his utmost, in the } \\
\text { course of person-to-person dialogue with his patient, to persuade } \\
\text { him to inform his family, would be reprehensible, particularly when } \\
\text { such information was needed to avoid dramatic outcomes }\end{array}$ \\
\hline Germany & $\begin{array}{l}\text { German Society of Human Genetics } \\
(2000)\end{array}$ & $\begin{array}{l}\text { Geneticists who press for the information to be relayed ... violate } \\
\text { patient autonomy }\end{array}$ \\
\hline $\begin{array}{l}\text { United } \\
\text { Kingdom }\end{array}$ & Human Genetics Commission (2000) & $\begin{array}{l}\text { Clinics may support and indeed encourage the process of family } \\
\text { communication and genetic counsellors may give advice on how } \\
\text { such information may be disseminated to those for whom it may be } \\
\text { most relevant }\end{array}$ \\
\hline
\end{tabular}

Table 3 Summary of guidelines

Should genetic health professionals identify at-risk family members?

Location Organization

Recommendation

Regional European Society of Human Genetics (2003)

Genetic services should support the identification of and care for relatives who are at risk of serious genetic disorders, but who may not have been directly referred, so that they too may receive well-informed genetic counselling and guidance on preventive and therapeutic actions if required

United Kingdom

Nuffield Council on Bioethics (1993) Kingdom

Human Genetics Commission (2000)
The kinds of information and procedures that people need to help them decide whether or not to be screened for a genetic disorder may be summarised as follows: information about the implications of screening positive (abnormal) for their future and existing children and for other family members

... genetic counsellors may give advice on how such information may be disseminated to those for whom it may be most relevant information with family members. An individual's moral obligation to their at-risk family members is presented as a compelling argument, supported by kinship bonds and an assumed desire to protect family members from harm. ${ }^{21,28,34}$ One publication states that an individual would be 'morally condemnable' if they withheld information from their family. ${ }^{27}$ The European Commission also illustrates that individuals may not be free to withhold genetic information due to family pressure. ${ }^{35}$ For a summary of guidelines, see Table 4 .

Should genetic health professionals assist individuals to inform family members? Recommendations addressing the provision of support to individuals who are informing their family members range from unambiguous statements that suggest the use of written materials ${ }^{28,37}$ to more open-ended suggestions that state support should be offered to individuals who are communicating genetic information. $^{31,39}$ Three organisations discuss the option of having the genetic health professional communicate the genetic information to family members at the client's request. $^{25,28,34}$ This suggestion is offered as a solution to clients who 'would prefer not to contact family members personally'25 and who 'may feel embarrassed about transmitting bad news', ${ }^{34}$ or where 'direct communication between family members is not an acceptable option' ${ }^{28}$ For a summary of guidelines, see Table 5 .

\section{Discussion}

The 19 guidelines included in this review address some aspects of genetic health professionals' practice concerning their client's genetic information and the ensuing familial implications. However, the national human genetics societies, do not provide detailed guidance about how genetic health professionals should support clients who are communicating genetic information. Other national human genetics societies may have published guidelines addressing this. However, the guidelines were either not available on their websites or their websites were in a language other than English. 
Table 4 Summary of guidelines

Do individuals have a moral obligation to inform family members?

Location Organization Recommendation

Australia National Health and Medical Research

Council (2000)

France National Consultative Ethics Committee for health and life sciences (2003)

Germany Committee for public relations and ethical issues of the German Society of Human Genetics (2000)

mendation

... in deciding not to disclose such information to relatives, an individual will need to balance carefully their right to privacy with the fact that disclosure could lead to the avoidance of a substantial chance of harm to a relative

For a person to withhold information that would have been required to avoid or treat in a timely way a genetic disease which threatens collateral relatives appears in principal to be morally condemnable In this respect a moral obligation of family members to share their knowledge of their genetic make-up can be seen, as well as a moral obligation of partners to inform each other of their medical genetic problems, insofar as the latter concern children they may have in common

United Kingdom Genetic Interest Group (1998)

An ethical imperative to share information People would then be encouraged to act ethically, but not forced to do so against their will

Table 5 Summary of guidelines

Should genetic health professionals assist individuals to inform family members?

Location Organization

International

World Health Organization (2003)

Australia

United Kingdom

United States of America

Institute of Medicine (1994)

\section{Recommendation}

The professional should offer people the option of having the professional tell the relatives, at the person's request. If the relatives live at a distance, the geneticist should offer referrals to professionals living near the relatives who can tell them, again at the individual's request

Support in conveying genetic information to at risk relatives should be offered

Most individuals express a desire for pedigree information and genetic test results to be made available to other family members to assist in diagnosis and medical care, even if that individual would prefer not to contact family members personally but asks health professionals to take on this role Mechanisms should be developed to aid a tested individual in informing his/her spouse and relatives about the individual's genetic status and informing relatives about genetic risks. These mechanisms would include the use of written materials, referrals for counseling, and so forth
The UK Nuffield Council on Bioethics and the French National Consultative Ethics Committee for Health and Life Sciences provide comprehensive and insightful discussion regarding the genetic health professionals' need to adoptive a directive stance and seek to persuade clients to disclose genetic information. These organisations also discuss the moral obligations individuals face when deciding whether to communicate, and the need for genetic health professionals to assist clients by identifying at-risk family members. Alternatively, many organisations focus on recommendations that address situations of nondisclosure of genetic information to family members. ${ }^{23,32}$

Research in the area of communication of genetic information in families readily illustrates that clients report high frequencies of communication to first- and second-degree relatives and less communication to those that are more distantly related. ${ }^{4,9}$ In contrast, research involving family members revealed a lack of understanding and awareness that a genetic condition was present in their family. ${ }^{18}$ This supports the notion that clients do attempt to communicate genetic information to family members; however, this role can be daunting and despite best efforts is undertaken poorly. ${ }^{18}$ Other research documenting how frequently clients report non-disclosure to genetic health professionals $^{6}$ found only 65 reported cases of nondisclosure out of 40000 clients attending genetics clinics over a 1-year period internationally. Therefore, the reported frequency of non-disclosure accounts for $<1 \%$ of all genetics consults, and despite this figure being reliant on an honest portrayal of the familial situation by clients to the attending counsellor, ${ }^{6}$ it would seem the overwhelming majority of clients report disclosing genetic information to their family members.

Given that the literature suggests that the majority of consultations will involve clients who will attempt to communicate genetic information to family members, and 
that many organisations focus more greatly on nondisclosure rather than communication, it is important to redress this imbalance by providing more comprehensive guidelines and recommendations to genetic health professionals to assist their clients when undertaking communication of genetic information. It is timely for the human genetics societies to develop and publish more in-depth discussions on this topic, similar to the publications emanating from the bioethics committees. ${ }^{27,30}$ Some issues for consideration may include: the need for genetic health professionals to be directive in their counselling so that clients are encouraged to communicate genetic information; to identify family members who are at risk of also inheriting the genetic condition; to encourage discussion with clients about their personal responsibilities to their family members; and the provision of further support after consultation, which may assist with the communication process.

Guidelines also fail to advise whether practice should differ given the variation of familial implications inherent in different genetic conditions. Clinical practice is highly variable as implications for at-risk relatives may include the availability of surveillance and/or treatment, the risk of serious disease in future generations or an unpreventable fatal condition. Guidelines or recommendations addressing practice for specific conditions would be useful, given this variation, and further research in this area would assist with the development of these guidelines.

The majority of the organisations reviewed contain some discussion about the familial implications that are inherent in genetic information. These preliminary discussions are fairly generic with some, but not all, organisations using this initial discussion as a platform for further recommendations about the client's role as a communicator and/or the genetic health professional's role as a facilitator of this process.

Guidelines for medical genetics and genetic counselling practice strongly emphasise that clients should be counselled in a non-directive manner, ${ }^{39}$ which is in accordance with the current ethos of non-paternalistic practice in medicine. However, contrary to this, many of the guidelines strongly encourage genetic health professionals to be directive with their clients when discussing the communication of genetic information. Practising in a directive manner may be justified in this area of genetic counselling to better ensure family members are made aware of their genetic risks.

Although many organisations discuss the familial implications of genetic information and the need for directive counselling when encouraging clients to inform their family members, few explicate the need for genetic health professionals to assist clients by identifying the at-risk relatives to whom the information should be given. Although many genetic health professionals may already undertake this task in their practice, the guidelines could be more insistent.

Contiguous to these issues of clarifying genetic health professionals' practice is the issue regarding clients' responsibilities to family members. It is well documented in the literature that clients report communicating genetic information to family members due to possessing a duty of care and/or a moral obligation ${ }^{21}$ towards their relatives. ${ }^{40}$ Therefore, guidelines need to better address how genetic health professionals discuss clients' responsibilities and direct them to pass on genetic information.

A number of the publications also mention the need for genetic health professionals to provide support to their clients beyond the consultation. Two guidelines, the Australian National Health and Medical Research Coun$\mathrm{Cil}^{28}$ and the US Institute of Medicine, ${ }^{37}$ suggest that written letters could be provided to relatives with information about the genetic condition. As mentioned previously, individuals are often burdened with the responsibility of informing family ${ }^{40}$ and attempts to communicate may result in a poor understanding of the genetic information being disseminated. ${ }^{18}$ Consequently, any support provided from the genetics service to individuals may be well received.

\section{Conclusion}

None of the guidelines, reports and recommendations reviewed provided a comprehensive overview of the process involved when clients receive genetic test results and are being counselled about the familial implications. The primary gap identified in the guidelines is the need for genetic health professionals to assist clients by identifying at-risk relatives, and the options for continued support while disseminating genetic information. Second, there is a lack of guidelines that address the differences in clinical practice due to the varying familial implications inherent in genetic conditions.

To develop more comprehensive guidelines, research is needed to investigate the current practice of genetic health professionals when caring for patients with genetic conditions, with varying familial implications. Further research exploring families' experiences of communicating genetic information would also assist with the development of evidence-based guidelines and it would subsequently be beneficial for the practice of medical genetics for the human genetics societies to review their guidelines, given this is becoming an increasingly topical and important area.

\section{Acknowledgements}

We thank the Murdoch Childrens Research Institute for their support and the Australian Research Council for funding this project. 


\section{References}

1 OMIM: OMIM statistics for August 23, 2006, 2006, http:// www.ncbi.nlm.nih.gov/Omim/mimstats.html.

2 Sorenson JR, Jennings-Grant T, Newman J: Communication about carrier testing within hemophilia A families. Am J Med Genet Part C-Semin Med Genet 2003; 119C: 3-10.

3 Hallowell N, Foster C, Eeles R, Ardern-Jones A, Murday V, Watson $\mathrm{M}$ : Balancing autonomy and responsibility: the ethics of generating and disclosing genetic information. J Med Ethics 2003; 29: 74-79.

4 Claes E, Evers-Kiebooms G, Boogaerts A, Decruyenaere M, Denayer L, Legius E: Communication with close and distant relatives in the context of genetic testing for hereditary breast and ovarian cancer in cancer patients. Am J Med Genet Part A 2003; 116A: 11-19.

5 Falk MJ, Dugan RB, O'Riordan MA, Matthews AL, Robin NH: Medical geneticists' duty to warn at-risk relatives for genetic disease. Am I Med Genet Part A 2003; 120: 374-380.

6 Clarke A, Richards M, Kerzin-Storrar L et al: Genetic professionals' reports of nondisclosure of genetic risk information within families. Eur J Human Genet 2005; 13: 556-562.

7 Dugan RB, Wiesner GL, Juengst ET, O'Riordan M, Matthews AL, Robin NH: Duty to warn at-risk relatives for genetic disease: genetic counselors' clinical experience. Am J Med Genet Part C-Semin Med Genet 2003; 119C: $27-34$

8 Forrest K, Simpson SA, Wilson BJ et al: To tell or not to tell: barriers and facilitators in family communication about genetic risk. Clin Genet 2003; 64: 317-326.

9 Forrest Keenan K, Simpson SA, Wilson BJ et al: It's their blood not mine': who's responsible for (not) telling relatives about genetic risk? Health, Risk Soc 2005; 7: 209-226.

10 Green RM, Thomas AM: Whose gene is it? A case discussion about familial conflict over genetic testing for breast cancer. J Genet Counsel 1997; 6: 245-254.

11 Hakimian R: Disclosure of Huntington's disease to family members: the dilemma of known but unknowing parties. Genet Test 2000; 4: 359-364.

12 Godard B, Hurlimann T, Letendre M, Egalite N, BRCAs I: Guidelines for disclosing genetic information to family members: from development to use. Fam Cancer 2006; 5: 103-116.

13 Wagner Costalas J, Itzen M, Malick J et al: Communication of BRCA1 and BRCA2 results to at-risk relatives: a cancer risk assessment program's experience. Am J Med Genet Part C, Semin Med Genet 2003; 119: 11-18.

14 Ormond KE, Mills PL, Lester LA, Ross LF: Effect of family history on disclosure patterns of cystic fibrosis carrier status. Am J Med Genet Part C-Semin Med Genet 2003; 119C: 70-77.

15 McGivern B, Everett J, Yager GG, Baumiller RC, Hafertepen A, Saal HM: Family communication about positive BRCA1 and BRCA2 genetic test results. Genet Med 2004; 6: 503-509.

16 Costalas JW, Itzen M, Malick J et al: Communication of BRCA1 and BRCA2 results to at-risk relatives: a cancer risk assessment program's experience. Am J Med Genet Part C-Semin Med Genet 2003; 119C: $11-18$

17 Miesfeldt S, Cohn WF, Jones SM, Ropka ME, Weinstein JC: Breast cancer survivors' attitudes about communication of breast cancer risk to their children. Am J Med Genet Part C-Semin Med Genet 2003; 119C: 45-50.

18 Sermijn E, Goelen G, Teugels E et al: The impact of proband mediated information dissemination in families with a BRCA1/2 gene mutation. J Med Genet 2004; 41: e23.

19 Svendsen MN, Koch L: Genetics and prevention: a policy in the making. New Genet Soc 2006; 25: 51-68.

20 de Wert G: Whose information is it anyway? Eur J Human Genet 2005; 13: 397-398.
21 Committee for Public Relations and Ethical Issues of the German Society of Human Genetics, reg. soc.: Positional paper of the German Society of Human Genetics, 2000; 1-13.

22 Human Genetics Society of Australasia: Privacy Implications of Genetic Testing 1999, http://hgsa.com.au/images/UserFiles/ Attachments/PrivacyImplicationsofGeneticTesting1.pdf.

23 The American Society of Human Genetics Social Issues Subcommittee on Familial Disclosure: ASHG statement: Professional disclosure of familial genetic information. Am J Human Genet 1998; 62: 474-483.

24 Matsuda I, Niikawa N, Sato K et al: Guidelines for genetic testing. J Human Genet 2001; 46: 163-165.

25 Royal College of Physicians, Royal College of Pathologists, British Society for Human Genetics: Consent and Confidentiality in Genetic Practice: Guidance on Genetic Testing and Sharing Genetic Information. London: RCP, RCPath, BSHG, Report of the Joint Committee on Medical Genetics 2005.

26 European Society of Human Genetics: Provision of genetic services in Europe: current practices and issues - recommendations of the European Society of Human Genetics. E J Human Genet 2003; 11: S2-S4.

27 National Consultative Ethics Committee for Health and Life Sciences: Regarding the Obligation to Disclose Genetic Information of Concern to the Family in the Event of Medical Necessity. France: National Consultative Ethics Committee for Health and Life Sciences, 2003.

28 National Health and Medical Research Council (NHMRC): Ethical Aspects of Human Genetic Testing: An Information Paper. Canberra: National Health and Medical Research Council, 2000.

29 International Bioethics Committee (IBC): Article 14: Privacy and Confidentiality: International Declaration on Human Genetic Data. Paris: United Nations Educational, Scientific, and Culteral Organization, 2003.

30 Nuffield Council on Bioethics: Genetic Screening: Ethical Issues. London: Nuffield Council on Bioethics, 1993.

31 Human Genetics Commission: Whose Hands on Your Genes? London: Department of Health, 2000.

32 President's Commission for the Study of Ethical Problems in Medicine and Biomedical and Behavioral Research: Screening and Counseling for Genetic Conditions: A Report on Ethical, Legal and Social Implications of Genetic Screening, Counseling, and Education Programs. US Government Printing Office: Washington, DC, 1982.

33 United Nations Economic and Social Council: Resolution 2004/9: Genetic Privacy and Non-Discrimination. Geneva: United Nations Economic and Social Council, 2004.

34 Wertz DC, Fletcher JC, Berg K: Review of Ethical Issues in Medical Genetics. Geneva: World Health Organization, 2003.

35 European Commission: Ethical, Legal and Social Aspects of Genetic Testing: Research, Development and Clinical Applications. Luxemburg: European Commission, 2004.

36 Council of Europe: Recommendation No. R(92)3 of the Committee of Ministers to member states on genetic testing and screening for health care purposes. Int J Bioethics 1992; 3 (4): $255-257$.

37 Andrews LB, Fullarton JE, Holtzman NA: Assessing Genetic Risks: Implications for Health and Social Policy. Washington, DC: National Academy Press, 1994.

38 Genetic Interest Group: Confidentiality Guidelines. London: Genetic Interest Group, 1998.

39 Human Genetics Society of Australasia: Guidelines for the Practice of Genetic Counselling 1999, http://hgsa.com.au/images/UserFiles/ Attachments/GuidelinesforthePracticeofGeneticCounselling.pdf.

40 Green J, Richards M, Murton F, Statham H, Hallowell N: Family Communication and Genetic Counseling: The Case of Hereditary Breast and Ovarian Cancer. J Genet Counsel 1997; 6: 45-60. 